\title{
Eating disorders are associated with increased risk of fall injury and fracture in Swedish men and women
}

\author{
K. F. Axelsson ${ }^{1,2} \cdot$ M. N. Woessner ${ }^{3} \cdot$ H. Litsne ${ }^{1} \cdot$ M. Wheeler ${ }^{4} \cdot$ A. Flehr ${ }^{4} \cdot$ A. J. King ${ }^{4} \cdot$ M. Kalén $^{5} \cdot$ L. Vandenput $^{1,4}$. $^{1}$ \\ M. Lorentzon ${ }^{1,4,6}$
}

Received: 30 September 2021 / Accepted: 18 January 2022 / Published online: 27 January 2022

(c) The Author(s) 2022

\begin{abstract}
Summary In this retrospective cohort study, men and women with eating disorders $(n=8867)$ had higher risk of injurious falls and hip fractures than age, sex, and county-matched controls $(n=88670)$.

Introduction Eating disorders have been associated with decreased bone mineral density and increased fracture risk, but the association with fall injuries without fracture has not previously been investigated. Furthermore, fracture risk in men with eating disorders has been insufficiently studied.

Methods In the present study, 8867 patients (9.4\% men) with a diagnosed eating disorders and 88670 age-, sex-, and countymatched controls were investigated.

Results The mean (standard deviation) age of the patients and controls was 41.6 (13.7) years and the follow-up time 9.6 (5.2, 14.4) years (median, interquartile range) for patients and $10.1(5.5,14.2)$ years for controls. The proportions of injurious falls without fracture (17.3\% vs. $9.0 \%)$ and of hip fracture (1.6\% vs. $0.7 \%)$ were substantially greater in patients with an eating disorder than in their corresponding population controls. In an unadjusted Cox proportional hazards model, individuals with an eating disorder had a higher risk of injurious falls without fracture (Hazard ratio (HR) 95\% confidence interval (CI): 2.07 (1.96-2.18), and hip fracture (HR 2.30 (1.92-2.75)) than the risk observed in the controls. The HR for any investigated outcome associated with an eating disorder did not differ by sex or age (interaction term $p>0.10$ ). The risk of injurious falls without fracture and hip fracture was increased in both women (HR 2.07 (1.95-2.19) and HR 2.41 (1.98-2.93), respectively) and men (HR 2.09 (1.76-2.49) and HR 1.84(1.12-3.02), respectively), with an eating disorder.

Conclusion The risk of injurious falls without fracture and of hip fracture is increased in both women and men with eating disorders, indicating measures to prevent both falls and fractures are important in these patients, regardless of age and sex.
\end{abstract}

Keywords Eating disorders $\cdot$ Falls $\cdot$ Fracture

M. Lorentzon

mattias.lorentzon@medic.gu.se;

mattias.lorentzon@acu.edu.au

1 Sahlgrenska Osteoporosis Centre, Institute of Medicine, Sahlgrenska Academy, University of Gothenburg,

Gothenburg, Sweden

2 Region Västra Götaland, Närhälsan Norrmalm Health Centre, Skövde, Sweden

3 Institute for Health and Sport (IHES), Victoria University, Melbourne, Australia
4 Mary McKillop Institute for Health Research, Australian Catholic University, Melbourne, Australia

5 Region Västra Götaland, Department of Psychiatry, Skaraborgs Hospital, Skövde, Sweden

6 Region Västra Götaland, Geriatric Medicine, Sahlgrenska University Hospital, Mölndal, Building K, 6th Floor, 43180 Mölndal, Sweden 


\section{Introduction}

Eating disorders are psychiatric disorders, including anorexia nervosa, bulimia nervosa, and binge eating disorder, which are defined by abnormal eating habits that negatively impact a person's mental and physical health [1]. Anorexia nervosa is a serious mental disorder characterized by a disturbed body image and/or fear of weight gain, which often leads to behaviors aiming to reduce body weight such as dietary restrictions and excessive physical activity [2]. In bulimia nervosa, body weight is usually normal or elevated, and binge eating episodes with compensatory behavior to avoid weight gain are typical [3]. The prevalence of eating disorders is higher in females than in males, and in Western countries, the prevalence of anorexia nervosa and bulimia nervosa in females ranges from 0.1 to $5.7 \%$ and 0.3 to $7.3 \%$, respectively [4].

Abnormally low body weight as a result of malnutrition or an eating disorder negatively impacts multiple organ systems, including the cardiovascular and central nervous system, as well as the bone [5, 6]. Anorexia nervosa is associated with lower bone mineral density (BMD) of both the spine and hip, increased cortical porosity, deteriorated trabecular bone microstructure, and reduced bone strength $[7,8]$. Patients with bulimia nervosa have less severely affected bone and present with lower spine BMD but normal hip BMD [7]. Since anorexia nervosa often affects young individuals, peak bone mass accrual can be impaired, with deleterious and mostly irreversible reductions in bone mass [9]. In anorexia nervosa, the negative impact on bone metabolism is mainly attributed to impaired gonadal function with low levels of estradiol and testosterone, but is also due to relative hypercortisolemia, resistance to growth hormone as well as other affected hormonal systems. Furthermore, severe malnutrition in anorexia nervosa deprives the skeleton of calcium, protein, and vitamin $\mathrm{D}$, all of which are vital for bone metabolism and skeletal health [6].

An increased risk of fracture has been observed in patients with anorexia nervosa but the results are conflicting regarding bulimia nervosa $[5,10,11]$. It has also been hypothesized that due to low caloric intake, patients with anorexia nervosa may be at increased risk of falls, due to increased orthostatic vital sign changes or to syncopal episodes [9]. Furthermore, women with anorexia nervosa but not with bulimia nervosa had lower muscle strength than age-matched controls, indicating impaired physical function, which could increase the risk of falls, in anorexia nervosa. Falls resulting in injuries other than fractures are also clinically relevant, since they are associated with a large health care burden, disability, financial cost, and patient suffering $[12,13]$. The impact of anorexia nervosa or bulimia nervosa on falls risk or risk of injurious falls without fracture has not previously been investigated. Due to the lower prevalence of eating disorder and fractures in men than in women, very limited data regarding the risk of fractures, especially hip fractures, is available in men with an eating disorder [11].

The main aim of this large, national, retrospective cohort study was to investigate the risk of injurious falls and fractures in 8,867 non-obese men and women diagnosed with an eating disorder from 1998 to 2017, and 88,670 age- and sex-matched controls in Sweden. An additional aim was to determine if these associations were independent of sex and age.

\section{Materials and methods}

This was a retrospective cohort study utilizing national medical registers in Sweden to identify non-obese patients who were diagnosed with an eating disorder between 1998 and 2017.

\section{Study design}

All non-obese (ICD-10 E66) patients with an eating disorder (ICD-10 F50) diagnosed at hospitals in Sweden between January 1, 1998, and December 31, 2017, were included in the present analysis. While further specification of eating disorder diagnoses was not available on an individual level, summary level data provided by the National Board of Health and Welfare (Socialstyrelsen) revealed that during the investigated time period, the F50 diagnosis was further composed of unspecified eating disorder (F50.9; 53\%), bulimia nervosa (F50.2; 19\%), anorexia nervosa (F50.0; 17\%), and other eating disorder categories (F50.1, F50.3, F50.4, F50.5, and F50.8; in total $11 \%$ ), classified according to ICD-10 [14]. Each eating disorder case was assigned ten population controls matched on birth year, sex, and county. Controls were assigned the same start date as their corresponding case and only controls without a previous eating disorder diagnosis were selected. The risk of injurious falls and fractures was investigated. The follow-up time was censored for end of study (December 31, 2017), emigration, and death. In order to perform Cox analyses with extensive adjustment for confounders, including the Charlson comorbidity index and medication data, a subset of the patient cohort was used. Since the Swedish Prescribed Drug Register started in 2005, to achieve a minimum of 1 year medication history and a 5-year history of medical diagnoses, only the 4,820 patients with a first eating disorder diagnosis between July 1, 2006, and December 31, 2017, and 48,200 age-, sex-, and countymatched controls were included. 


\section{Data sources}

Several Swedish national medical and population registers were combined in order to study clinical characteristics and outcomes in patients with an eating disorder and in the population controls. The Swedish Patient Register was used to retrieve diagnoses for eating disorder, comorbidities, fractures, and fall injuries without fractures (both inpatient and outpatient visits). Data on prescribed medications was retrieved from the Swedish Prescribed Drug Register, and data regarding socioeconomic factors and death from Statistics Sweden. All inhabitants in Sweden are assigned a unique personal identification at birth or at the time of immigration, enabling linkage between the different registers. The study was approved by the Swedish Ethical Review Authority.

\section{Definition of outcomes}

All data on reported outcomes and comorbidities were collected from hospital visits and admissions using ICD-10 codes and are listed in Appendix Table 1. Medical history prior to each included individual's start of follow-up was based on a 5-year history. Fall injury was defined as any event with an injury (S00-T14) and a fall code (W00-W19) but without a fracture code [15]. For the fracture outcomes, all non-pathological fracture diagnoses regardless of type of trauma were included. Fracture data was refined in multiple steps. First, fracture diagnoses with a simultaneous code indicating a revisit (Z09, Z47, Z48) and hip fracture diagnoses without a simultaneous code for surgical procedure were discarded. Second, a washout period of 5 months was used, so that if a fracture diagnosis referring to the same skeletal site was repeated within a period of 5 months, the latter diagnosis was discarded to avoid including codes from revisits. Incident hip fracture included fractures of the femoral head, neck, trochanter, or subtrochanteric part of the femur accompanied with a code for surgical procedure (NFB, NFC, or NFJ). Incident major osteoporotic fracture (MOF) was defined as a fracture of the hip, vertebrae, proximal humerus, wrist, or pelvis.

\section{Statistical analyses}

A large selection of covariates (listed in Table 1) representing prevalent illnesses and prescribed medications with potential impact on an included individual's comorbidity and risk of fracture or injurious falls were selected. The Charlson comorbidity index was calculated to summarize and quantify comorbidity [16]. To investigate and present differences in baseline characteristics, standardized differences were calculated. Incident rates per 1000 person-years were calculated to enable comparison of incidence despite different followup lengths. Cox regression models were used to calculate hazard ratios. In contrast to logistic regression, Cox regression uses the length of each individual's follow-up period. The Cox assumption of proportional hazards was tested using a time-dependent Cox model with a linear interaction term between time and group variable for eating disorder diagnosis. The proportional hazards criterion was fulfilled. Interaction analyses were performed using Cox models, with interaction terms eating disorder $\times$ sex and eating disorder $\times$ age. Subgroup analyses were performed with stratification for sex. In the subset cohort, 1:1 propensity score matching was performed using R-Studio Version 1.2.5033 for Mac and the MatchIt package. Statistical analyses were performed using IBM SPSS software version 26 and Stata version SE 16.0 for Mac. $P$-values lower than 0.05 were considered significant. For interaction terms, $p$-values lower than 0.10 were considered significant.

\section{Results}

In the present study, 8867 patients with a diagnosed eating disorder and 88,670 age-, sex-, and county-matched controls who had never been diagnosed with an eating disorder were investigated. The mean (standard deviation) age of the patients with an eating disorder and controls was 41.6 (13.7) years, and the majority of patient and controls were women (90.6\%). Patients with an eating disorder were more likely to have received sickness benefits but were less likely to be of non-Nordic origin (Table 1).

In the complete cohort, patients with an eating disorder were followed for 9.6 $(5.2,14.4)$ years (median, interquartile range) and controls for $10.1(5.5,14.2)$ years. The proportions of injurious falls without fracture (17.3\% vs. 9.0\%), of any fracture (17.9\% vs. 9.7\%), major osteoporotic fracture $(7.3 \%$ vs $3.7 \%)$, and hip fracture (1.6\% vs. $0.7 \%)$ were significantly $(p<0.001)$ greater in patients with an eating disorder than in their corresponding population controls. Patients with an eating disorder sustained 1531 non-skeletal fall injuries, of which 434 were head injuries (Appendix Table 2). The proportion of non-skeletal injurious falls was greater in patients than in controls, regardless of injury type. Similarly, incident rates of injurious falls, any fracture, major osteoporotic fracture, and hip fracture were considerably higher in patients with an eating disorder than in the controls (Table 2).

In an adjusted Cox proportional hazards model, patients with an eating disorder had a higher risk of injurious falls (Hazard ratio (HR) 95\% confidence interval (CI): 1.94 (1.83-2.05)), any fracture (HR 1.94 (1.84-2.05)), major osteoporotic fracture (HR 2.18 (2-2.37)), and hip fracture (HR 3.06 (2.55-3.67)) than the controls (Table 2, Fig. 1).

The HR for any investigated outcome associated with an eating disorder did not differ by sex or age (interaction term 
Table 1 Baseline characteristics

\begin{tabular}{|c|c|c|c|c|c|c|c|}
\hline & & Complete cohor & t (1998-2017) & & Subset cohort $(2$ & 006-2017) & \\
\hline & & Controls & Eating Disorder & SMD & Controls & Eating disorder & SMD \\
\hline & & $N=88670$ & $N=8867$ & & $N=48200$ & $N=4820$ & \\
\hline Age, y & Mean (SD) & $41.6(13.7)$ & $41.6(13.7)$ & 0 & $45.9(12.6)$ & $45.9(12.6)$ & 0 \\
\hline Age $20-39$ & $n(\%)$ & $46,790(52.8 \%)$ & $4679(52.8 \%)$ & 0 & $17,340(36.0 \%)$ & $1734(36.0 \%)$ & 0 \\
\hline Age $40-59$ & $n(\%)$ & $32,760(36.9 \%)$ & $3276(36.9 \%)$ & 0 & $24,460(50.7 \%)$ & $2446(50.7 \%)$ & 0 \\
\hline Age $\geq 60$ & $n(\%)$ & $9120(10.3 \%)$ & $912(10.3 \%)$ & 0 & $6400(13.3 \%)$ & $640(13.3 \%)$ & 0 \\
\hline Female sex & $n(\%)$ & $80,360(90.6 \%)$ & $8036(90.6 \%)$ & 0 & $43,160(89.5 \%)$ & $4316(89.5 \%)$ & 0 \\
\hline Non-Nordic citizenship at birth & $n(\%)$ & $12,298(13.9 \%)$ & $818(9.2 \%)$ & -0.146 & $7064(14.7 \%)$ & $486(10.1 \%)$ & -0.139 \\
\hline Sickness benefits & $n(\%)$ & $12,696(14.3 \%)$ & $3954(44.6 \%)$ & 0.704 & $6223(12.9 \%)$ & $1998(41.5 \%)$ & 0.677 \\
\hline Charlson Comorbidity index & Mean (SD) & - & - & - & $0.2(0.8)$ & $0.4(1.2)$ & 0.227 \\
\hline$=1$ & $n(\%)$ & - & - & - & $2047(4.2 \%)$ & $432(9.0 \%)$ & 0.191 \\
\hline$=2$ & $n(\%)$ & - & - & - & $1669(3.5 \%)$ & $281(5.8 \%)$ & 0.113 \\
\hline$\geq 3$ & $n(\%)$ & - & - & - & $834(1.7 \%)$ & $223(4.6 \%)$ & 0.166 \\
\hline Osteoporosis (M80-M81) & $n(\%)$ & - & - & - & $259(0.5 \%)$ & $104(2.2 \%)$ & 0.141 \\
\hline Secondary osteoporosis & $n(\%)$ & - & - & - & $1018(2.1 \%)$ & $278(5.8 \%)$ & 0.189 \\
\hline Osteoporosis medication, $1 \mathrm{y}$ history & $n(\%)$ & - & - & - & $589(1.2 \%)$ & $87(1.8 \%)$ & 0.048 \\
\hline Calcium vitamin $\mathrm{D}, 1 \mathrm{y}$ history & $n(\%)$ & - & - & - & $629(1.3 \%)$ & $159(3.3 \%)$ & 0.133 \\
\hline $\begin{array}{l}\text { Previous alcohol related disease, 5y his- } \\
\text { tory }\end{array}$ & $n(\%)$ & - & - & - & $447(0.9 \%)$ & $439(9.1 \%)$ & 0.381 \\
\hline Previous rheumatoid arthritis, $5 \mathrm{y}$ history & $n(\%)$ & - & - & - & $329(0.7 \%)$ & $53(1.1 \%)$ & 0.044 \\
\hline $\begin{array}{l}\text { Previous prednisolone use ( } \geq 5 \mathrm{mg} / \\
\text { day, } \geq 3 \text { months) }\end{array}$ & $n(\%)$ & - & - & - & $1525(3.2 \%)$ & $245(5.1 \%)$ & 0.097 \\
\hline Previous fracture & $n(\%)$ & - & - & - & $4333(9.0 \%)$ & $730(15.1 \%)$ & 0.190 \\
\hline multiple ( $\geq 2$ occasions, 5y history) & $n(\%)$ & - & - & - & $357(0.7 \%)$ & $99(2.1 \%)$ & 0.112 \\
\hline recent (1y history) & $n(\%)$ & - & - & - & $615(1.3 \%)$ & $166(3.4 \%)$ & 0.143 \\
\hline Previous fall injury & $n(\%)$ & - & - & - & $3912(8.1 \%)$ & $689(14.3 \%)$ & 0.197 \\
\hline multiple ( $\geq 2$ occasions, $5 y$ history) & $n(\%)$ & - & - & - & $506(1.0 \%)$ & $121(2.5 \%)$ & 0.111 \\
\hline recent (1y history) & $n(\%)$ & - & - & - & $513(1.1 \%)$ & $120(2.5 \%)$ & 0.108 \\
\hline Antidepressants (N06A), 1y history & $n(\%)$ & - & - & - & $3754(7.8 \%)$ & $1974(41.0 \%)$ & 0.837 \\
\hline Antipsychotics (N05A), 1y history & $n(\%)$ & - & - & - & $561(1.2 \%)$ & $422(8.8 \%)$ & 0.355 \\
\hline Anxiolytics (N05B), 1y history & $n(\%)$ & - & - & - & $1279(2.7 \%)$ & $955(19.8 \%)$ & 0.565 \\
\hline Hypnotics \& sedatives (N05C), 1y history & $n(\%)$ & - & - & - & $2285(4.7 \%)$ & $1273(26.4 \%)$ & 0.626 \\
\hline
\end{tabular}

The complete cohort includes all patients with an eating disorder diagnosis and the subset cohort includes all patients with an eating disorder diagnosis with at least 1 year of medication history and $\geq 5$ years history of diagnoses. Standardized mean differences (SMD) were calculated as $\left(\right.$ mean $_{\mathrm{ED}}-$ mean $\left._{\text {controls }}\right) / \sqrt{ }\left(\left(\mathrm{SD}_{\mathrm{ED}}^{2}+\mathrm{SD}_{\text {controls }}^{2}\right) / 2\right)$. All $p$-values were $<0.001$ apart from age and sex

$p>0.10)$. In a sex-stratified analysis, incidence rates and the risk of injurious falls without fracture, any fracture, major osteoporotic fracture, and hip fracture were substantially increased both in men and women with an eating disorder diagnosis, compared to controls (Table 3). These associations remained highly similar and significant after adjustments for confounders.

In the subset of the cohort, patients with an eating disorder had substantially greater comorbidity, were more likely to have osteoporosis and diseases linked to secondary osteoporosis, and have alcohol-related diseases, as well as having a considerably higher proportion of prevalent fractures and fall injuries, than their age- and sex-matched controls (Table 1). The proportion being prescribed medications linked to falls (antidepressants, antipsychotics, anxiolytics, hypnotics, and sedatives) was substantially higher among eating disorder patients than in controls. Cox regression models were performed in order to evaluate if patients with an eating disorder had increased risk of injurious falls and fractures, when considering additional confounders. In a multivariable Cox regression (model 1), patients with eating disorder had increased risk of injurious falls (HR 1.44 (1.30-1.59)), any fracture (HR 1.43 (1.29-1.57)), major osteoporotic fracture (HR 1.46 (1.25-1.70)), and hip fracture (HR 2.79 (2.03-3.82); Table 4). The increased risk for all these 
Table 2 Associations between an Eating Disorder diagnosis, fall injury, and fracture
Fig. 1 The cumulative hazard of injurious falls (A), any fracture (B), major osteoporotic fracture (C), and hip fracture (D) for patients with an eating disorder and controls presented as fractions (0 to 1$)$

\begin{tabular}{|c|c|c|c|}
\hline Outcome & $\begin{array}{l}\text { Controls } \\
N=88670\end{array}$ & Eating disorder $N=8867$ & $p$-value \\
\hline \multicolumn{4}{|l|}{ Injurious falls without fracture } \\
\hline Events, $n(\%)$ & $7974(9.0 \%)$ & $1531(17.3 \%)$ & $<0.001$ \\
\hline Per 1000 person-years $(95 \% \mathrm{CI})$ & $9.49(9.28-9.70)$ & $19.6(18.7-20.6)$ & $<0.001$ \\
\hline Unadjusted Cox, HR (95\% CI) & Ref & $2.07(1.96-2.18)$ & $<0.001$ \\
\hline Adjusted Cox, HR (95\% CI) & Ref & $1.94(1.83-2.05)$ & $<0.001$ \\
\hline \multicolumn{4}{|l|}{ Any fracture } \\
\hline Events, $n(\%)$ & $8633(9.7 \%)$ & $1584(17.9 \%)$ & $<0.001$ \\
\hline Per 1000 person-years $(95 \% \mathrm{CI})$ & $10.3(10.1-10.5)$ & $20.3(19.3-21.3)$ & $<0.001$ \\
\hline Unadjusted Cox, HR (95\% CI) & Ref & $1.97(1.87-2.08)$ & $<0.001$ \\
\hline Adjusted Cox, HR (95\% CI) & Ref & $1.94(1.84-2.05)$ & $<0.001$ \\
\hline \multicolumn{4}{|l|}{ Major osteoporotic fracture } \\
\hline Events, $n(\%)$ & $3298(3.7 \%)$ & $645(7.3 \%)$ & $<0.001$ \\
\hline Per 1000 person-years $(95 \% \mathrm{CI})$ & $3.78(3.65-3.91)$ & $7.66(7.09-8.27)$ & $<0.001$ \\
\hline Unadjusted Cox, HR (95\% CI) & Ref & $2.03(1.86-2.21)$ & $<0.001$ \\
\hline Adjusted Cox, HR (95\% CI) & Ref & $2.18(2.00-2.37)$ & $<0.001$ \\
\hline \multicolumn{4}{|l|}{ Hip fracture } \\
\hline Events, $n(\%)$ & $636(0.7 \%)$ & $142(1.6 \%)$ & $<0.001$ \\
\hline Per 1000 person-years $(95 \% \mathrm{CI})$ & $0.71(0.66-0.77)$ & $1.64(1.39-1.93)$ & $<0.001$ \\
\hline Unadjusted Cox, HR (95\% CI) & Ref & $2.30(1.92-2.75)$ & $<0.001$ \\
\hline Adjusted Cox, HR (95\% CI) & Ref & $3.06(2.55-3.67)$ & $<0.001$ \\
\hline
\end{tabular}

All subjects from the complete cohort were included in the analyses. The Cox proportional hazards model used was adjusted for year of inclusion, age, sex, non-Nordic citizenship, and sickness benefits
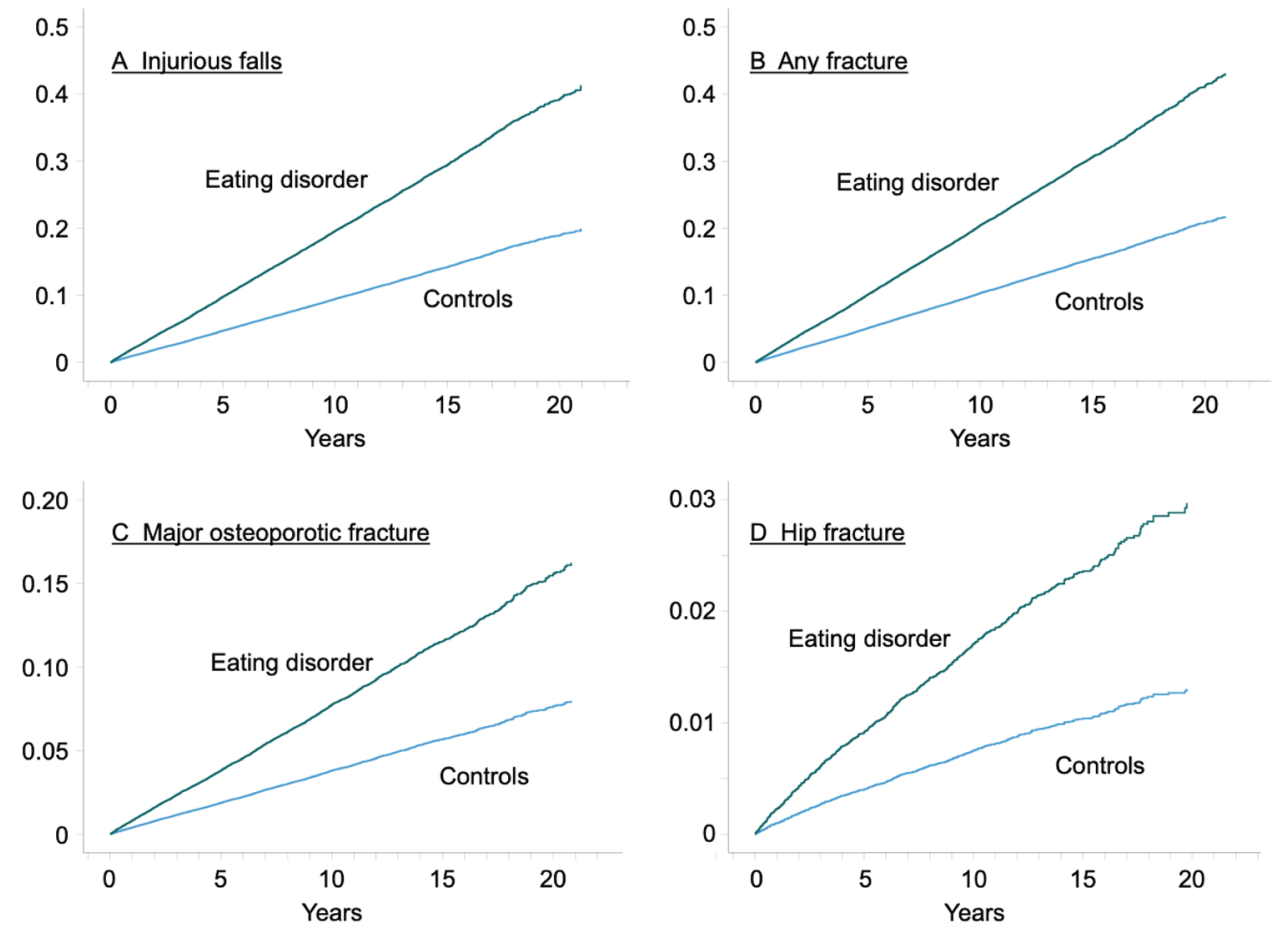

outcomes in patients with eating disorders remained significant but was attenuated when adding adjustments for medications linked to falls (model 2). Similarly, the increased risk for all investigated outcomes remained significant, but attenuated when comparing the patients with eating disorders to $1: 1$ propensity score matched controls (Appendix Table 3-4). 
Table 3 Sex-stratified associations between an eating disorder diagnosis, injurious falls and fracture

\begin{tabular}{|c|c|c|c|c|c|c|}
\hline & \multicolumn{3}{|l|}{ Women } & \multicolumn{3}{|l|}{ Men } \\
\hline & Control $N=80360$ & $\begin{array}{l}\text { Eating disorder } \\
N=8036\end{array}$ & $p$-value & $\begin{array}{l}\text { Control } \\
N=8310\end{array}$ & $\begin{array}{l}\text { Eating disorder } \\
N=831\end{array}$ & $p$-value \\
\hline \multicolumn{7}{|l|}{ Injurious falls } \\
\hline Events, $n(\%)$ & $7140(8.9 \%)$ & $1380(17.2 \%)$ & $<0.001$ & $834(10 \%)$ & $151(18.2 \%)$ & $<0.001$ \\
\hline Per 1000 person-years $(95 \% \mathrm{CI})$ & $9.25(9.04-9.47)$ & $19.1(18.2-20.2)$ & $<0.001$ & $12.1(11.3-13)$ & $25.4(21.7-29.8)$ & $<0.001$ \\
\hline Unadjusted Cox, HR (95\% CI) & Ref & $2.07(1.95-2.19)$ & $<0.001$ & Ref & $2.09(1.76-2.49)$ & $<0.001$ \\
\hline Adjusted Cox, HR (95\% CI) & Ref & $1.92(1.81-2.04)$ & $<0.001$ & Ref & $2.10(1.75-2.51)$ & $<0.001$ \\
\hline \multicolumn{7}{|l|}{ Any fracture } \\
\hline Events, $n(\%)$ & $7733(9.6 \%)$ & $1441(17.9 \%)$ & $<0.001$ & $900(10.8 \%)$ & $143(17.2 \%)$ & $<0.001$ \\
\hline Per 1000 person-years $(95 \% \mathrm{CI})$ & $10.0(9.8-10.3)$ & $20.0(19.0-21.0)$ & $<0.001$ & $13.2(12.3-14)$ & $24.4(20.7-28.7)$ & $<0.001$ \\
\hline Unadjusted Cox, HR (95\% CI) & Ref & $1.99(1.88-2.11)$ & $<0.001$ & Ref & $1.85(1.55-2.20)$ & $<0.001$ \\
\hline Adjusted Cox, HR (95\% CI) & Ref & $1.95(1.84-2.06)$ & $<0.001$ & Ref & $1.81(1.51-2.18)$ & $<0.001$ \\
\hline \multicolumn{7}{|l|}{ Major osteoporotic fracture } \\
\hline Events, $n(\%)$ & $3014(3.8 \%)$ & $595(7.4 \%)$ & $<0.001$ & $284(3.4 \%)$ & $50(6.0 \%)$ & $<0.001$ \\
\hline Per 1000 person-years $(95 \% \mathrm{CI})$ & $3.77(3.64-3.90)$ & $7.64(7.05-8.28)$ & $<0.001$ & $3.88(3.46-4.36)$ & $7.90(6.01-10.4)$ & $<0.001$ \\
\hline Unadjusted Cox, HR (95\% CI) & Ref & $2.03(1.86-2.21)$ & $<0.001$ & Ref & $2.03(1.51-2.74)$ & $<0.001$ \\
\hline Adjusted Cox, HR (95\% CI) & Ref & $2.15(1.96-2.35)$ & $<0.001$ & Ref & $2.49(1.83-3.38)$ & $<0.001$ \\
\hline \multicolumn{7}{|l|}{ Hip fracture } \\
\hline Events, n (\%) & $527(0.7 \%)$ & $125(1.6 \%)$ & $<0.001$ & $109(1.3 \%)$ & $17(2.0 \%)$ & $<0.001$ \\
\hline Per 1000 person-years $(95 \% \mathrm{CI})$ & $0.64(0.59-0.70)$ & $1.55(1.30-1.84)$ & $<0.001$ & $1.48(1.22-1.78)$ & $2.72(1.71-4.31)$ & 0.02 \\
\hline Unadjusted Cox, HR (95\% CI) & Ref & $2.41(1.98-2.93)$ & $<0.001$ & Ref & $1.84(1.12-3.02)$ & 0.02 \\
\hline Adjusted Cox, HR (95\% CI) & Ref & $3.06(2.52-3.73)$ & $<0.001$ & Ref & $2.83(1.70-4.71)$ & $<0.001$ \\
\hline
\end{tabular}

All subjects from the complete cohort were included in the analyses. Cox proportional hazards models were adjusted for year of inclusion, age, sex, non-Nordic citizenship, and sickness benefits

\section{Discussion}

In this large, retrospective national cohort study, we found that both men and women with an eating disorder had increased risk of injurious falls without fracture, any fracture, major osteoporotic fracture, and hip fracture, as compared to their age and sex-matched population controls. These associations were observed for men and women separately and were not dependent on age.

Fall rates increase with age and falls are the leading cause of nonfatal and fatal injury in older adults [17]. In community-living older persons, fall-related injuries are the most prominent cause of disability and likelihood of long-term nursing home admissions [18]. In the present study, patients with an eating disorder were younger (mean age 41.6 years) but were followed for up to 20 years. During this period, over $17 \%$ of the patients with an eating disorder sustained an injurious fall without a fracture, a proportion approximately double that of the control population, indicating that injurious falls constitute a very common and clinically important (the affected patients had to seek medical attention for their fall injury) problem for patients with eating disorders. Both head injuries and injuries at other locations were much more common in patients with eating disorders, indicating that the condition leads to increased rates of falling. The association was highly similar for men and women, without any interaction between injurious falls and sex, suggesting that the increased risk with an eating disorder is highly similar in both sexes, although the prevalence is lower in men.

The increased propensity to fall could be due to hypotension, arrhythmias, hypoglycemia, peripheral neuropathy, and conditions all related to anorexia nervosa. Similar but less severe conditions can be found in bulimia nervosa [1, 19]. Altogether, it is conceivable that eating disorders can increase the risk of falls and injuries resulting from falls, although the clinical impact of eating disorders on injurious falls has not previously been reported.

A much more frequent use of medications linked to falls, including antidepressants, anxiolytics, antipsychotics, sedatives, and hypnotics [20], was observed in patients with eating disorders than in the controls. The risk of fractures and injurious falls was still elevated but slightly attenuated in patients with eating disorders when adjusting for these medications in the Cox model (subset analysis, Table 4), indicating that a more frequent use of these medications contribute to the increased risk observed in eating disorder patients. In the subset analysis, the patients with baseline June 2006 or before were excluded, i.e., the 
Table 4 Associations between an eating disorder diagnosis, injurious falls, and fracturessubset analyses to allow multivariable adjustment

\begin{tabular}{|c|c|c|c|}
\hline Outcome & $\begin{array}{l}\text { Controls } \\
N=48200\end{array}$ & $\begin{array}{l}\text { Eating disorder } \\
N=4820\end{array}$ & $p$-value \\
\hline \multicolumn{4}{|l|}{ Injurious falls } \\
\hline Events, $n(\%)$ & $3085(6.4 \%)$ & $582(12.1 \%)$ & $<0.001$ \\
\hline Per 1000 person-years $(95 \% \mathrm{CI})$ & $10.8(10.4-11.2)$ & $22.0(20.3-23.9)$ & $<0.001$ \\
\hline Unadjusted Cox, HR (95\% CI) & Ref & $2.04(1.86-2.23)$ & $<0.001$ \\
\hline Adjusted Cox, HR (95\% CI) & Ref & $1.93(1.76-2.12)$ & $<0.001$ \\
\hline Multivariable Cox model 1, HR (95\% CI) & Ref & $1.44(1.30-1.59)$ & $<0.001$ \\
\hline Multivariable Cox model 2, HR (95\% CI) & Ref & $1.33(1.20-1.47)$ & $<0.001$ \\
\hline \multicolumn{4}{|l|}{ Any fracture } \\
\hline Events, $n(\%)$ & $3377(7.0 \%)$ & $602(12.5 \%)$ & $<0.001$ \\
\hline Per 1000 person-years $(95 \% \mathrm{CI})$ & $11.9(11.5-12.3)$ & $22.6(20.9-24.5)$ & $<0.001$ \\
\hline Unadjusted Cox, HR (95\% CI) & Ref & $1.91(1.75-2.08)$ & $<0.001$ \\
\hline Adjusted Cox, HR (95\% CI) & Ref & $1.86(1.70-2.03)$ & $<0.001$ \\
\hline Multivariable Cox model 1, HR (95\% CI) & Ref & $1.43(1.29-1.57)$ & $<0.001$ \\
\hline Multivariable Cox model 2, HR (95\% CI) & Ref & $1.34(1.21-1.48)$ & $<0.001$ \\
\hline \multicolumn{4}{|l|}{ Major osteoporotic fracture } \\
\hline Events, $n(\%)$ & $1318(2.7 \%)$ & $231(4.8 \%)$ & $<0.001$ \\
\hline Per 1000 person-years $(95 \% \mathrm{CI})$ & $4.5(4.27-4.75)$ & $8.26(7.26-9.40)$ & $<0.001$ \\
\hline Unadjusted Cox, HR (95\% CI) & Ref & $1.83(1.59-2.11)$ & $<0.001$ \\
\hline Adjusted Cox, HR (95\% CI) & Ref & $1.92(1.66-2.22)$ & $<0.001$ \\
\hline Multivariable Cox model 1, HR (95\% CI) & Ref & $1.46(1.25-1.70)$ & $<0.001$ \\
\hline Multivariable Cox model 2, HR (95\% CI) & Ref & $1.41(1.20-1.65)$ & $<0.001$ \\
\hline \multicolumn{4}{|l|}{ Hip fracture } \\
\hline Events, $n(\%)$ & $255(0.5 \%)$ & $60(1.2 \%)$ & $<0.001$ \\
\hline Per 1000 person-years $(95 \% \mathrm{CI})$ & $0.86(0.76-0.97)$ & $2.10(1.63-2.71)$ & $<0.001$ \\
\hline Unadjusted Cox, HR (95\% CI) & Ref & $2.44(1.84-3.23)$ & $<0.001$ \\
\hline Adjusted Cox, HR (95\% CI) & Ref & $3.46(2.60-4.60)$ & $<0.001$ \\
\hline Multivariable Cox model 1, HR (95\% CI) & Ref & $2.79(2.03-3.82)$ & $<0.001$ \\
\hline Multivariable Cox model 2, HR (95\% CI) & Ref & $2.69(1.94-3.71)$ & $<0.001$ \\
\hline
\end{tabular}

All subjects diagnosed with an eating disorder between 2006 and 2017 from the subset cohort were included in the analyses. The adjusted Cox model included adjustment for year of inclusion, age, sex, nonNordic citizenship, and sickness benefits. In the multivariable model 1, adjustment was added for previous fracture (any, recent, and multiple), previous non-skeletal fall injury (any, recent, multiple), number of previous admissions, Charlson comorbidity index, osteoporosis diagnosis, secondary osteoporosis, alcoholrelated illness, rheumatoid arthritis, oral prednisolone use, osteoporosis medication, and calcium and vitamin D supplements. In the multivariable model 2, adjustment was also added for antipsychotic, anxiolytic, hypnotic/sedative, and antidepressant medications patients with the longest follow-up, longest time with illness, were excluded, resulting in similar associations as the whole group, however with slightly lesser magnitude as expected.

Normally, high-intensity exercise has beneficial effects on physical function and BMD [21], but in anorexia, this effect could be absent or the opposite if there is overtraining present $[6,22]$. In addition, with increased exposure, the risk of falls could also be affected adversely in these patients. Extreme exercise is common in anorexia nervosa and it is therefore conceivable that exercise habits could have influenced the risk of injurious falls in the present analysis, but due to lack of data on exercise, this hypothesis could not be investigated [23].
The incidence of fragility fracture increases with age and is about twice as high in women than in men [24, 25]. Fractures often lead to loss of function, disability, and chronic pain, which have deleterious effects on the affected person's quality of life [26-28]. Several previous studies have found an increased risk of fractures at most sites in women with anorexia nervosa, but only limited data is available regarding men with the condition. In one large study of men and women in the UK, men with anorexia nervosa had increased risk of vertebral fractures but the study lacked statistical power to evaluate the risk of hip fracture, with only 7 affected men included in the follow-up. In the present study, all patients with any eating disorder from the entire Swedish population, 40 years and older, were included, yielding the 
hitherto largest population of men with an eating disorder studied. Men with an eating disorder had a substantially greater risk of any fracture, major osteoporotic fracture, and hip fracture than their age-matched controls. As expected, the risk of fractures was also considerably higher in women with an eating disorder than in their age-matched population controls, with the greatest increased risk observed for hip fracture. For both men and women, the risk of hip fracture was approximately 3 times higher in patients with an eating disorder than in their age- and sex-matched population controls. Over the duration of the study, $17-18 \%$ of men and women with an eating disorder had a fracture, emphasizing the size and importance of eating disorder-related fractures.

In the subset of patients $(n=4820)$ with an eating disorder diagnosed between 2006 and 2017, the proportions of prevalent fracture and injurious falls were considerably larger than in their age- and sex-matched controls, suggesting that the disease or its related comorbidities had been present before the time of diagnosis. A sensitivity analysis was performed to investigate if the increased risk of fractures and injurious falls was due to known comorbidities. Results revealed that the association between an eating disorder, fractures, and injurious falls maintained and was not markedly attenuated in fully adjusted models.

The potential negative impact of both anorexia nervosa and bulimia nervosa on spine BMD and for anorexia nervosa on hip BMD as well has been previously reported [7], although the association between bulimia and low BMD has not been found in all studies [29]. The detrimental effects of severe malnutrition and underweight, as seen in anorexia nervosa, on BMD has been well documented, and are likely influenced by duration of amenorrhea but the mechanisms for lower BMD in bulimia nervosa are more obscure [30].

A limitation of the present study is the lack of specification of type of eating disorder diagnosis on a patient level in the present analysis. This prevents conclusions regarding the relative risk of fracture and injurious falls in anorexia nervosa and bulimia separately. In most previous studies investigating the risk of fracture in eating disorders, anorexia nervosa has been associated with the most profound risk increase $[10,11]$. Thus, it is likely that the risk estimates for patients with eating disorders in the herein presented results underestimate the true risk increase in patients with anorexia nervosa. Although we were able to perform sensitivity analysis in a subset of individuals with a large amount of data on possible confounders, including medication and diseases, we did not have access to all relevant risk factors (e.g., physical activity habits, smoking, heredity, body mass index, and BMD) for fractures and/or falls [31-33], which could have influenced the results. Due to the lack of these important confounders, the present study is not able to in detail study potential mechanisms behind the observed associations between eating disorder and studied outcomes. Furthermore, using ICD-10 codes to identify patients with eating disorder has been argued to have several shortcomings, including lack of consistency in assigned diagnosis codes, resulting in many patients diagnosed in the subcategories (such as "other specified," "unspecified," or "atypical"), and failure to recognize the full range of clinical manifestations of eating and feeding disorders [34]. However, it could be argued that the present analysis should not have been affected by this inherent limitation with ICD-10 coding for eating disorder, since only the main diagnosis (F50) code was most commonly used.

However, the current study also has many strengths. It is by far the largest study to date in terms of the number of included patients, length of follow-up, and number of events, to investigate the association between eating disorders and fracture risk in both men and women $[5,10,11]$. This study is the first to document a statistically significant increase in the risk of hip fractures in men with eating disorders. The present study also constitutes the hitherto only populationbased cohort examining the risk of non-skeletal fall injuries in patients with eating disorders.

In conclusion, men and women with an eating disorder have a substantially higher risk of fall injury without fracture, any fracture, major osteoporotic fracture, and hip fracture compared to their age- and sex-matched controls.

Supplementary Information The online version contains supplementary material available at https://doi.org/10.1007/s00198-022-06312-2.

Funding Open access funding provided by University of Gothenburg.

\section{Declarations}

Conflicts of interest Dr Axelsson has received lecture fees from Lilly, Meda/Mylan and Amgen. Prof Lorentzon has received lecture fees from Astellas, Amgen, Lilly, UCB Pharma, Radius Health, Meda/ Mylan, GE-Lunar and Santax Medico/Hologic. Mr Litsne and Drs Woessner, Wheeler, Flehr, King, Kalén, and Vandenput have no conflicts of interest.

Open Access This article is licensed under a Creative Commons Attribution-NonCommercial 4.0 International License, which permits any non-commercial use, sharing, adaptation, distribution and reproduction in any medium or format, as long as you give appropriate credit to the original author(s) and the source, provide a link to the Creative Commons licence, and indicate if changes were made. The images or other third party material in this article are included in the article's Creative Commons licence, unless indicated otherwise in a credit line to the material. If material is not included in the article's Creative Commons licence and your intended use is not permitted by statutory regulation or exceeds the permitted use, you will need to obtain permission directly from the copyright holder. To view a copy of this licence, visit http://creativecommons.org/licenses/by-nc/4.0/. 


\section{References}

1. Treasure J, Duarte TA, Schmidt U (2020) Eating disorders. Lancet 395:899-911

2. Zipfel S, Giel KE, Bulik CM, Hay P, Schmidt U (2015) Anorexia nervosa: aetiology, assessment, and treatment. Lancet Psychiatry 2:1099-1111

3. Wade TD (2019) Recent research on Bulimia Nervosa. Psychiatr Clin North Am 42:21-32

4. Makino M, Tsuboi K, Dennerstein L (2004) Prevalence of eating disorders: a comparison of Western and non-Western countries. MedGenMed 6:49

5. Frølich J, Winkler LA, Abrahamsen B, Bilenberg N, Hermann AP, Støving RK (2020) Fractures in women with eating disordersIncidence, predictive factors, and the impact of disease remission: cohort study with background population controls. Int J Eat Disord 53:1080-1087

6. Fazeli PK, Klibanski A (2018) Effects of anorexia nervosa on bone metabolism. Endocr Rev 39:895-910

7. Robinson L, Aldridge V, Clark EM, Misra M, Micali N (2016) A systematic review and meta-analysis of the association between eating disorders and bone density. Osteoporos Int 27:1953-1966

8. Faje AT, Karim L, Taylor A et al (2013) Adolescent girls with anorexia nervosa have impaired cortical and trabecular microarchitecture and lower estimated bone strength at the distal radius. J Clin Endocrinol Metab 98:1923-1929

9. Chidiac CW (2019) An update on the medical consequences of anorexia nervosa. Curr Opin Pediatr 31:448-453

10. Vestergaard P, Emborg C, Stoving RK, Hagen C, Mosekilde L, Brixen K (2002) Fractures in patients with anorexia nervosa, bulimia nervosa, and other eating disorders-a nationwide register study. Int J Eat Disord 32:301-308

11. Nagata JM, Golden NH, Leonard MB, Copelovitch L, Denburg MR (2017) Assessment of Sex differences in fracture risk among patients with anorexia nervosa: a population-based cohort study using the health improvement network. J Bone Miner Res 32:1082-1089

12. Vos T, Flaxman AD, Naghavi M et al (2012) Years lived with disability (YLDs) for 1160 sequelae of 289 diseases and injuries 1990-2010: a systematic analysis for the Global Burden of Disease Study 2010. Lancet 380:2163-2196

13. Murray CJ, Atkinson C, Bhalla K et al (2013) The state of US health, 1990-2010: burden of diseases, injuries, and risk factors. JAMA 310:591-608

14. WHO (2004) The ICD-10 classification of mental and behavioural disorders: clinical descriptions and diagnostic guidelines, 2nd edn. World Health Organization, Geneva

15. Axelsson KF, Nilsson AG, Wedel H, Lundh D, Lorentzon M (2017) Association between alendronate use and hip fracture risk in older patients using oral prednisolone. JAMA 318:146-155

16. Charlson ME, Pompei P, Ales KL, MacKenzie CR (1987) A new method of classifying prognostic comorbidity in longitudinal studies: development and validation. J Chronic Dis 40:373-383

17. Phelan EA, Ritchey K (2018) Fall prevention in communitydwelling older adults. Ann Intern Med 169:Itc81-itc96

18. Gill TM, Murphy TE, Gahbauer EA, Allore HG (2013) Association of injurious falls with disability outcomes and nursing home admissions in community-living older persons. Am J Epidemiol $178: 418-425$
19. Gibson D, Workman C, Mehler PS (2019) Medical complications of anorexia nervosa and bulimia nervosa. Psychiatr Clin North Am 42:263-274

20. de Jong MR, Van der Elst M, Hartholt KA (2013) Drug-related falls in older patients: implicated drugs, consequences, and possible prevention strategies. Ther Adv Drug Saf 4:147-154

21. Kistler-Fischbacher M, Weeks BK, Beck BR (2021) The effect of exercise intensity on bone in postmenopausal women (part 2): a meta-analysis. Bone 143:115697

22. Frisch RE, Gotz-Welbergen AV, McArthur JW, Albright T, Witschi J, Bullen B, Birnholz J, Reed RB, Hermann H (1981) Delayed menarche and amenorrhea of college athletes in relation to age of onset of training. JAMA 246:1559-1563

23. Trott M, Jackson SE, Firth J, Jacob L, Grabovac I, Mistry A, Stubbs B, Smith L (2021) A comparative meta-analysis of the prevalence of exercise addiction in adults with and without indicated eating disorders. Eat Weight Disord - Stud Anorexia Bulimia Obes 26:37-46

24. Sambrook P, Cooper C (2006) Osteoporosis. Lancet 367:2010-2018

25. Kanis JA, Oden A, Johnell O, Jonsson B, de Laet C, Dawson A (2001) The burden of osteoporotic fractures: a method for setting intervention thresholds. Osteoporos Int 12:417-427

26. Johansson L, Sundh D, Nilsson M, Mellstrom D, Lorentzon M (2018) Vertebral fractures and their association with healthrelated quality of life, back pain and physical function in older women. Osteoporos Int 29:89-99

27. Bliuc D, Nguyen TV, Eisman JA, Center JR (2014) The impact of nonhip nonvertebral fractures in elderly women and men. J Clin Endocrinol Metab 99:415-423

28. Borgstrom F, Karlsson L, Ortsater G et al (2020) Fragility fractures in Europe: burden, management and opportunities. Arch Osteoporos 15:59

29. Sundgot-Borgen J, Bahr R, Falch JA, Schneider LS (1998) Normal bone mass in bulimic women. J Clin Endocrinol Metab 83:3144-3149

30. Biller BM, Saxe V, Herzog DB, Rosenthal DI, Holzman S, Klibanski A (1989) Mechanisms of osteoporosis in adult and adolescent women with anorexia nervosa. J Clin Endocrinol Metab 68:548-554

31. Nilsson M, Eriksson J, Larsson B, Oden A, Johansson H, Lorentzon M (2016) Fall risk assessment predicts fall-related injury, hip fracture, and head injury in older adults. J Am Geriatr Soc 64:2242-2250

32. Kanis JA (2002) Diagnosis of osteoporosis and assessment of fracture risk. Lancet 359:1929-1936

33. Lord SR, Sherrington C, Menz HB, Close JCT (2007) Falls in older people: risk factors and strategies for prevention. Cambridge University Press, Cambridge

34. Claudino AM, Pike KM, Hay P et al (2019) The classification of feeding and eating disorders in the ICD-11: results of a field study comparing proposed ICD-11 guidelines with existing ICD10 guidelines. BMC Med 17:93

Publisher's note Springer Nature remains neutral with regard to jurisdictional claims in published maps and institutional affiliations. 